\title{
Anti-inflammatory, antinociceptive and ulcerogenic activity of a zinc-diclofenac complex in rats
}

\author{
L.H. Santos ${ }^{1}$, C.A.O. Feres ${ }^{1}$, \\ F.H. Melo ${ }^{1}$, M.M. Coelho ${ }^{2}$, \\ M.S. Nothenberg', \\ S. Oga ${ }^{4}$ and C.A. Tagliati ${ }^{1}$
}

\author{
Departamentos de ${ }^{1}$ Análises Clínicas e Toxicológicas and \\ ${ }^{2}$ Produtos Farmacêuticos, Faculdade de Farmácia, \\ Universidade Federal de Minas Gerais, Belo Horizonte, MG, Brasil \\ Departamentos de ${ }^{3}$ Farmácia and ${ }^{4}$ Análises Clínicas e Toxicológicas, \\ Faculdade de Ciências Farmacêuticas, Universidade de São Paulo, \\ São Paulo, SP, Brasil
}

\section{Correspondence \\ C.A. Tagliati \\ Laboratório de Toxicologia \\ Experimental \\ Departamento de Análises Clínicas \\ e Toxicológicas \\ Faculdade de Farmácia, UFMG \\ Av. Olegário Maciel, 2360/613 \\ 30180-112 Belo Horizonte, MG \\ Brasil \\ Fax: +55-31-3339-7644 \\ E-mail: carlostagliati@ufmg.br \\ Presented at the XII Congresso Brasileiro de Toxicologia, Porto Alegre, RS, Brasil, 2001, and reported \\ in abstract form (Revista Brasileira de Toxicologia, 14 (Suppl): 101). \\ Research supported by CAPES}

Publication supported by FAPESP

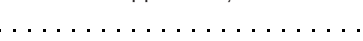

Received May 27, 2003

Accepted May 25, 2004

\begin{abstract}
We investigated the anti-inflammatory, antinociceptive and ulcerogenic activity of a zinc-diclofenac complex $(5.5$ or $11 \mathrm{mg} / \mathrm{kg}$ ) in male Wistar rats $(180-300 \mathrm{~g}, \mathrm{~N}=6)$ and compared it to free diclofenac $(5 \mathrm{or} 10 \mathrm{mg} /$ $\mathrm{kg}$ ) and to the combination of diclofenac (5 or $10 \mathrm{mg} / \mathrm{kg}$ ) and zinc acetate $(1.68$ or $3.5 \mathrm{mg} / \mathrm{kg})$. The carrageenin-induced paw edema and the cotton pellet-induced granulomatous tissue formation models were used to assess the anti-inflammatory activity, and the Hargreaves model of thermal hyperalgesia was used to assess the antinociceptive activity. To investigate the effect of orally or intraperitoneally (ip) administered drugs on cold-induced gastric lesions, single doses were administered before exposing the animals to a freezer $\left(-18^{\circ} \mathrm{C}\right)$ for $45 \mathrm{~min}$ in individual cages. We also evaluated the gastric lesions induced by multiple doses of the drugs. Diclofenac plus zinc complex had the same anti-inflammatory and antinociceptive effects as diclofenac alone. Gastric lesions induced by a single dose administered per os and $i p$ were reduced in the group treated with zinc-diclofenac when compared to the groups treated with free diclofenac or diclofenac plus zinc acetate. In the multiple dose treatment, the complex induced a lower number of the most severe lesions when compared to free diclofenac and diclofenac plus zinc acetate. In conclusion, the present study demonstrates that the zincdiclofenac complex may represent an important therapeutic alternative for the treatment of rheumatic and inflammatory conditions, as its use may be associated with a reduced incidence of gastric lesions.
\end{abstract}

Key words

- Diclofenac-zinc complex

- Gastric lesions

- Non-steroidal anti-

inflammatory drugs

- Ulcerogenesis

- Antinociception

\section{Introduction}

Non-steroidal anti-inflammatory drugs (NSAIDs) represent group of therapeutic drugs most frequently used in the world. Diclofenac, an NSAID synthesized by Ciba-Geigy about 30 years ago (1), is one of the medicines most frequently used in Brazil (2). Diclofenac has been used to alleviate the pain and edema associated with rheumatoid arthritis, osteoarthritis, spondylitis, and many other inflammatory conditions. It is also useful for the relief of dysmenorrhea and of the pain associated with surgery and neoplastic diseases (3).

Although diclofenac is usually well tolerated by patients, its use can result in some side 
effects, particularly those related to the gastrointestinal tract (4). Thus, some approaches have been devised to reduce the incidence of these side effects, including the use of different routes of administration (5), $\mathrm{H}_{2}$ receptor antagonists (6), pro-drugs (7), omeprazole and sucralfate (8), misoprostol (9), and selective cyclooxygenase 2 inhibitors (10).

Many experimental and clinical studies have demonstrated that zinc compounds may be useful to treat or prevent gastric ulcers (11-15). Rodrigues de la Serna and DíazRubio (16) showed that zinc acexamate markedly reduced the severity of gastric lesions induced by piroxicam in patients.

Since patients' compliance with the posologic scheme is one of the most important factors to determine the outcome of pharmacotherapy (17), mainly in long-term treatments, the search for medicines that associate anti-inflammatory and gastroprotective effects is important because it could avoid the co-administration of two drugs. Tagliati et al. (18) were the first to evaluate the antiinflammatory activity and the incidence of gastric lesions induced by piroxicam, an NSAID, complexed with zinc in rats. The anti-inflammatory activity of piroxicam was not changed when the drug was used as a complex with zinc, but the severity of gastric lesions was reduced in the group treated with the zinc complex. Similar results have been reported for zinc-tenoxicam (19).

In order to determine if the protective effect against gastric lesions by complex formation with zinc could be extended to other NSAIDs, we assessed the anti-inflammatory and ulcerogenic activity of a zincdiclofenac complex in experimental animals.

\section{Material and Methods}

Drugs

The following drugs were used: sodium diclofenac, 2-[(2,6-dichlorophenyl)amino] benzene acetic acid monosodium salt; [0(2,6-dichloroanilino)phenyl]acetic acid sodium salt (kindly donated by Química Intercontinental Farmacêutica, São Paulo, SP, Brazil), zinc-diclofenac (synthesized according to technique described by Cini et al. (20), zinc acetate (Merck, São Paulo, SP, Brazil), carboxymethylcellulose (CMC, Reagen, Rio de Janeiro, RJ, Brazil), carrageenin (Sigma, St. Louis, MO, USA), ethyl ether (Synth, São Paulo, SP, Brazil), sterile $0.9 \% \mathrm{NaCl}$ (Hypofarma, São Paulo, SP, Brazil).

\section{Animals}

Male Wistar rats (180-300 g) were used. The animals were kept in a light-controlled room on a 12-h light/dark cycle. Food and water were available ad libitum, except that the animals were fasted overnight before each experiment, although they continued to have free access to water. In the experiment for gastric lesions, the animals were placed in cages without sawdust, with free access to water but without contact with any residue. In each experimental protocol, the animals were divided into four groups $(\mathrm{N}=6)$ and treated with $0.5 \% \mathrm{CMC}$, a sodium diclofenac suspension in $0.5 \% \mathrm{CMC}$, a zinc-diclofenac suspension in $0.5 \% \mathrm{CMC}$, or a suspension of diclofenac plus zinc acetate in $0.5 \%$ CMC. The drugs were administered per os ( $p o$ ) or intraperitoneally (ip). The experimental protocols were approved by the Ethics Committee on Animal Experimentation (CETEA) of Universidade Federal de Minas Gerais.

\section{Evaluation of anti-inflammatory and antinociceptive effects}

Carrageenin-induced paw edema. Paw edema was induced by injecting $50 \mu 1$ of $1 \%$ carrageenin in saline into the subplantar region of the left hind paw. A similar volume of sterile saline was injected into the same region of the right hind paw. Paw volume 
was determined before each treatment (basal volume) and 2, 4 and $6 \mathrm{~h}$ after carrageenin injection using a plethysmometer (Model 7150, Ugo Basile, Varese, Italy). The drugs were administered $p o$ or $i p$ at the following doses: $10 \mathrm{mg} / \mathrm{kg}$ diclofenac, $11 \mathrm{mg} / \mathrm{kg}$ zincdiclofenac or $10 \mathrm{mg} / \mathrm{kg}$ diclofenac plus 3.35 $\mathrm{mg} / \mathrm{kg}$ zinc acetate, $2 \mathrm{~h}$ before the injection of carrageenin ( $\mathrm{N}=6$ for each group).

Formation of granulomatous tissue. Formation of granulomatous tissue was induced by subcutaneous $(s c)$ implantation of four equidistant cotton pellets (40 $\mathrm{mg}$ each) into the abdominal region of the animals under ether anesthesia, according to the technique described by Niemegeers et al. (21). Since this was a multiple dose study, lower doses were used. Diclofenac $(5 \mathrm{mg} / \mathrm{kg})$, zinc-diclofenac $(5.5 \mathrm{mg} / \mathrm{kg})$ or diclofenac $(5 \mathrm{mg} / \mathrm{kg})$ plus zinc acetate $(1.68 \mathrm{mg} / \mathrm{kg})$ was administered $p o$ daily for 7 days. On the seventh day, $4 \mathrm{~h}$ after the last administration, the animals were killed and the granulomatous tissue was removed and dried at $60^{\circ} \mathrm{C}$ for $24 \mathrm{~h}$. Granuloma weight was defined as the difference between the weight of the dry tissue and the weight of the initial implanted cotton pellet (160 mg) ( $\mathrm{N}=6$ for each group).

Nociceptive response induced by a thermal stimulus. The nociceptive response was assessed by the technique described by Hargraves et al. (22). One day before the experiment, the animals were placed in the nociceptive response apparatus (Model UB 7370, Ugo Basile) for $30 \mathrm{~min}$. On the day of the experiment, after another adaptation period of $30 \mathrm{~min}$, the basal latency for paw withdrawal induced by a thermal stimulus was determined. Diclofenac $(10 \mathrm{mg} / \mathrm{kg})$, zincdiclofenac $(11 \mathrm{mg} / \mathrm{kg})$, diclofenac $(10 \mathrm{mg} /$ $\mathrm{kg})$ plus zinc acetate $(3.35 \mathrm{mg} / \mathrm{kg})$ or a corresponding volume of $0.5 \% \mathrm{CMC}$ was administered po or ip. After $2 \mathrm{~h}, 1 \%$ carrageenin $(50 \mu 1)$ was injected into the subplantar region of the right hind paw. The paw withdrawal latency was again determined at 2, 4 and $6 \mathrm{~h}(\mathrm{~N}=6$ for each group).

\section{Evaluation of gastric lesions}

Two models were used to evaluate gastric lesions. In the first model, diclofenac (10 $\mathrm{mg} / \mathrm{kg})$, zinc-diclofenac $(11 \mathrm{mg} / \mathrm{kg})$, diclofenac $(10 \mathrm{mg} / \mathrm{kg})$ plus zinc acetate $(3.35 \mathrm{mg} /$ $\mathrm{kg}$ ) or a corresponding volume of $0.5 \% \mathrm{CMC}$ was administered po or ip. After $4 \mathrm{~h}$, the animals were transferred to a freezer $\left(-18^{\circ} \mathrm{C}\right)$ in individual cages, where they were kept for 45 min according to a modification (19) of the technique described by Rainsford (23). After this period, the animals were killed after exposure to ethylic ether and their stomachs removed ( $\mathrm{N}=6$ rats for each group).

In the second model, diclofenac $(5 \mathrm{mg} / \mathrm{kg})$, zinc-diclofenac $(5.5 \mathrm{mg} / \mathrm{kg})$, diclofenac $(5 \mathrm{mg} /$ $\mathrm{kg})$ plus zinc acetate $(1.68 \mathrm{mg} / \mathrm{kg})$ or a corresponding volume of $0.5 \% \mathrm{CMC}$ was administered po daily for 7 days. After $4 \mathrm{~h}$, the animals were killed and their stomachs removed.

To determine the number and severity of the gastric lesions, immediately after sacrifice the stomachs of the animals were opened and rinsed with $5 \mathrm{ml}$ saline. The stomachs were carefully examined under a stereoscopic microscope (Metrimpex-PZ Labimex, Budapest, Hungary) and the lesions were classified according to severity as follows: $1+$ (hyperemia and/or petechiae); $2+$ (hemorrhage with moderate erosion) and $3+$ (hemorrhage with extensive and severe lesions) (24). The number of lesions of each category was determined and the mean \pm SEM for each experimental group was presented. The technician who performed the scoring procedure did not know the treatment to which the animals had been submitted.

\section{Statistical analysis}

The nonparametric Mann-Whitney test was used to analyze the results of the gastric lesions. Parametric statistical analysis (oneway ANOVA) followed by the Duncan multiple comparison test was used to analyze the other results. Statistical significance was set at $\mathrm{P}<0.05$. 



Figure 1. Effect of diclofenac, zinc-diclofenac and diclofenac plus zinc acetate on paw edema after per os and intraperitoneal administration. Diclofenac $(10 \mathrm{mg} / \mathrm{kg})$, zinc-diclofenac $(11 \mathrm{mg} /$ $\mathrm{kg})$, diclofenac $(10 \mathrm{mg} / \mathrm{kg})$ plus zinc acetate $(3.35 \mathrm{mg} / \mathrm{kg})$ or the corresponding volume of $0.5 \%$ carboxymethylcellulose (control) was administered per os (A) and intraperitoneally (B) 30 min before injection of $1 \%$ carrageenin into the subplantar region of the left hindpaw. Each value represents the mean \pm SEM for 6 animals. ${ }^{*} \mathrm{P}<0.05$ compared to control; ${ }^{+} \mathrm{P}<$ 0.05 compared to the group treated with zinc-diclofenac (ANOVA and Duncan test).

\section{Results}

\section{Carrageenin-induced paw edema}

Carrageenin $(1 \%, 50 \mu l)$ induced a marked edema that reached its peak $4 \mathrm{~h}$ after injection. Previous po treatment with diclofenac, zinc-diclofenac or diclofenac plus zinc acetate induced the same extent of inhibition of carrageenin-induced edema (Figure 1A). Intraperitoneal administration of the drugs also inhibited carrageenin-induced edema (Figure 1B). The drugs were administered $p o$ or $i p$ at the following doses: diclofenac $(10 \mathrm{mg} /$ $\mathrm{kg})$, zinc-diclofenac $(11 \mathrm{mg} / \mathrm{kg})$ or diclofenac $(10 \mathrm{mg} / \mathrm{kg})$ plus zinc acetate $(3.35 \mathrm{mg} /$ $\mathrm{kg}), 2 \mathrm{~h}$ before the injection of carrageenin ( $\mathrm{N}=6$ for each group).

\section{Formation of granulomatous tissue}

Treatment for 7 days with diclofenac $(5$ $\mathrm{mg} \mathrm{kg}^{-1}$ day $\left.^{-1}\right)$, zinc-diclofenac $\left(5.5 \mathrm{mg} \mathrm{kg}^{-1}\right.$ day $\left.^{-1}\right)$ or diclofenac $\left(5 \mathrm{mg} \mathrm{kg}^{-1}\right.$ day $\left.^{-1}\right)$ plus zinc acetate $\left(1.68 \mathrm{mg} \mathrm{kg}^{-1} \mathrm{day}^{-1}\right)$ inhibited the formation of granulomatous tissue induced by implantation of $s c$ cotton pellets into the abdominal region (Table 1). The degree of inhibition was similar for all drugs.

\section{Nociceptive response induced by a thermal stimulus}

Carrageenin induced a reduction of paw withdrawal latency in response to a thermal stimulus. Per oral (Figure 2A) or ip (Figure 2B) administration of diclofenac $(10 \mathrm{mg} /$ $\mathrm{kg})$, zinc-diclofenac $(11 \mathrm{mg} / \mathrm{kg})$ or diclofenac $(10 \mathrm{mg} / \mathrm{kg})$ plus zinc acetate $(3.35 \mathrm{mg} /$ $\mathrm{kg}$ ) induced an antinociceptive effect.

\section{Effect of routes of administration of} diclofenac, zinc-diclofenac or diclofenac plus zinc acetate on the severity of gastric lesions induced by cold exposure in rats

As shown in Table 2, the severity of 
gastric lesions (levels $1+$ and $3+$ ) for the group treated with zinc-diclofenac $(11 \mathrm{mg} /$ $\mathrm{kg}$ ) po was less than that presented by the groups treated with diclofenac $(10 \mathrm{mg} / \mathrm{kg})$ or with the diclofenac $(10 \mathrm{mg} / \mathrm{kg})$ plus zinc acetate $(3.35 \mathrm{mg} / \mathrm{kg})$ combination. The severity of gastric lesions in the groups treated with diclofenac or diclofenac plus zinc acetate was similar at all levels $(1+, 2+$ and $3+)$. Table 3 shows that the severity of all gastric lesions in the group treated with zinc-diclofenac ip was less than that presented by the group treated with diclofenac alone. However, in comparison to the group treated with diclofenac plus zinc acetate, a significant difference was only observed for $1+$ lesions.

\section{Gastric lesions induced by po administration for 7 days}

As shown in Table 4, the severity of gastric lesions (level $3+$ ) induced by zincdiclofenac $(11 \mathrm{mg} / \mathrm{kg})$ was less than that induced by diclofenac $(10 \mathrm{mg} / \mathrm{kg})$ alone. The severity was also reduced for lesions $2+$ and $3+$ when compared to the severity of the lesions induced by diclofenac $(10 \mathrm{mg} / \mathrm{kg})$ plus zinc acetate $(3.35 \mathrm{mg} / \mathrm{kg})$.

\section{Discussion}

The results of the present study demonstrate that complex formation of diclofenac with zinc does not change the anti-inflammatory or antinociceptive activity of the drug, but reduces the severity of gastric lesions induced by this NSAID.

In the model of carrageenin-induced edema, diclofenac, zinc-diclofenac or the diclofenac plus zinc acetate combination inhibited the response in a similar manner. These results provide support to those reported by Tagliati et al. (18) and Nascimento et al. (19), who demonstrated that the antiinflammatory activity of piroxicam and tenoxicam was not changed by complexing with zinc. Similar results have also been reported
Table 1. Effect of diclofenac, zinc-diclofenac, and diclofenac plus zinc acetate on the formation of granulomatous tissue in rats.

\begin{tabular}{cccc}
\hline \multicolumn{4}{c}{ Granuloma weight $(\mathrm{mg})$} \\
\hline Control & Diclofenac & Zinc-diclofenac & Diclofenac + zinc acetate \\
\hline $351.4 \pm 10.1$ & $239.5 \pm 8.3^{\mathrm{a}}$ & $234.2 \pm 18.4^{\mathrm{a}}$ & $263.3 \pm 14.0^{\mathrm{a}}$
\end{tabular}

Diclofenac (5 mg kg-1 day $\mathrm{mg}^{-1}$ ), zinc-diclofenac $\left(5.5 \mathrm{mg} \mathrm{kg}^{-1}\right.$ day $\left.^{-1}\right)$, the association of diclofenac $\left(5 \mathrm{mg} \mathrm{kg}^{-1}\right.$ day $\left.^{-1}\right)$ plus zinc acetate $\left(1.68 \mathrm{mg} \mathrm{kg}^{-1}\right.$ day $\left.^{-1}\right)$ or the corresponding volume of $0.5 \%$ carboxymethylcellulose was administered po for 7 days. Data are reported as means \pm SEM for 6 animals.

asignificantly different in comparison to control group $(P<0.05$, ANOVA and Duncan test).

Table 2. Effect of diclofenac, zinc-diclofenac, and diclofenac plus zinc acetate on gastric lesions after per os administration.

\begin{tabular}{lcccr}
\hline \multicolumn{5}{c}{ Severity of gastric lesions } \\
\cline { 2 - 5 } Level & Control & Diclofenac & Zinc-diclofenac & $\begin{array}{r}\text { Diclofenac }+ \\
\text { zinc acetate }\end{array}$ \\
\hline $1+$ & $540.5 \pm 123.5$ & $1526 \pm 93.0^{\mathrm{a}, \mathrm{b}}$ & $292 \pm 51.6$ & $1384 \pm 67.8^{\mathrm{a}, \mathrm{b}}$ \\
$2+$ & $7.5 \pm 1.2$ & $16.5 \pm 3.7^{\mathrm{a}, \mathrm{b}}$ & $7.5 \pm 1.7$ & $14 \pm 1.2^{\mathrm{a}}$ \\
$3+$ & $1 \pm 0.4$ & $11.5 \pm 1.7^{\mathrm{a}, \mathrm{b}}$ & $3.5 \pm 1.6$ & $12.5 \pm 1.8^{\mathrm{a}, \mathrm{b}}$ \\
\hline
\end{tabular}

Diclofenac $(10 \mathrm{mg} / \mathrm{kg})$, zinc-diclofenac $(11 \mathrm{mg} / \mathrm{kg})$, the association of diclofenac (10 $\mathrm{mg} / \mathrm{kg}$ ) plus zinc acetate $(3.35 \mathrm{mg} / \mathrm{kg}$ ) or the corresponding volume of $0.5 \%$ carboxymethylcellulose (control) was administered per os $4 \mathrm{~h}$ before cold exposure $(4 \mathrm{~h}$, $-18^{\circ} \mathrm{C}$ ). Data are reported as means \pm SEM for 6 animals. Levels: $1+$ (hyperemia and/ or petechia); $2+$ (hemorrhage with moderate erosion); $3+$ (hemorrhage with extensive and severe lesions).

ap $<0.05$ compared to control; bP $<0.05$ compared to the group treated with zincdiclofenac (Mann-Whitney test).

Table 3. Effect of diclofenac, zinc-diclofenac, and diclofenac plus zinc acetate on gastric lesions after intraperitoneal administration.

\begin{tabular}{lccrr}
\hline \multicolumn{5}{c}{ Severity of gastric lesions } \\
\cline { 2 - 5 } Level & Control & Diclofenac & Zinc-diclofenac & $\begin{array}{r}\text { Diclofenac }+ \\
\text { zinc acetate }\end{array}$ \\
\hline $1+$ & $563.5 \pm 112.2$ & $1703 \pm 79.3^{\mathrm{a}, \mathrm{b}}$ & $670.5 \pm 77.7$ & $1521 \pm 69.0^{\mathrm{a}, \mathrm{b}}$ \\
$2+$ & $3 \pm 1.6$ & $8 \pm 0.9^{\mathrm{b}}$ & $4 \pm 0.9$ & $5 \pm 1.3$ \\
$3+$ & $0 \pm 0.2$ & $5 \pm 2.0^{\mathrm{a}, \mathrm{b}, \mathrm{c}}$ & $0.5 \pm 0.5$ & $1.5 \pm 0.7$ \\
\hline
\end{tabular}

Diclofenac $(10 \mathrm{mg} / \mathrm{kg})$, zinc-diclofenac $(11 \mathrm{mg} / \mathrm{kg})$, the association of diclofenac $(10$ $\mathrm{mg} / \mathrm{kg}$ ) plus zinc acetate $(3.35 \mathrm{mg} / \mathrm{kg}$ ) or the corresponding volume of $0.5 \%$ carboxymethylcellulose (control) was administered intraperitoneally $4 \mathrm{~h}$ before cold exposure $\left(4 \mathrm{~h},-18^{\circ} \mathrm{C}\right)$. Data are reported as means \pm SEM for 6 animals. See Table 2 for explanation of levels.

ap $<0.05$ compared to control; bP $<0.05$ compared to the group treated with zincdiclofenac; $\mathrm{CP}<0.05$ compared to the group treated with diclofenac plus zinc acetate (Mann-Whitney test). 
for naproxen (25). Bravo et al. (13) have also shown that simultaneous administration of acetylsalicylic acid and zinc does not alter the anti-inflammatory activity of this NSAID. However, Abou-Mohamed et al. (26) have demonstrated that the simultaneous administration of diclofenac plus zinc sulfate induces a higher inhibition of carrageenininduced edema than diclofenac alone. These investigators have also shown that zinc sul-

Table 4. Gastric lesions induced by a 7-day per os treatment.

\begin{tabular}{lccrr}
\hline \multicolumn{5}{c}{ Severity of gastric lesions } \\
\cline { 2 - 5 } Level & Control & Diclofenac & Zinc-diclofenac & $\begin{array}{r}\text { Diclofenac }+ \\
\text { zinc acetate }\end{array}$ \\
& & & \\
\hline $1+$ & $328.5 \pm 56.7$ & $423 \pm 51.6$ & $261.5 \pm 62.3$ & $311.5 \pm 89.5$ \\
$2+$ & $4.5 \pm 1.5$ & $27.5 \pm 7.8^{a}$ & $18.5 \pm 3.6^{a}$ & $41 \pm 9.7^{a}$ \\
$3+$ & $0 \pm 0$ & $8.5 \pm 3.1^{a, b}$ & $3 \pm 0.7$ & $10.5 \pm 1.6^{a, b}$ \\
\hline
\end{tabular}

Gastric lesions were induced by a 7-day po treatment with diclofenac $(5 \mathrm{mg} / \mathrm{kg})$, zincdiclofenac $(5.5 \mathrm{mg} / \mathrm{kg})$, the association of diclofenac $(5 \mathrm{mg} / \mathrm{kg})$ plus zinc acetate $(1.68$ $\mathrm{mg} / \mathrm{kg}$ ) or the corresponding volume of $0.5 \%$ carboxymethylcellulose (control). Data are reported as means \pm SEM for 6 animals. See Table 2 for explanation of levels. ap $<0.05$ compared to control; bP $<0.05$ compared to the group treated with zincdiclofenac (Mann-Whitney test). fate per se inhibited carrageenin-induced edema, indicating that this compound may present an intrinsic anti-inflammatory activity. The difference between our results, lack of enhancement of anti-inflammatory effect by simultaneous administration of zinc acetate and diclofenac, and those obtained by Abou-Mohamed et al. (26) may be due to the approximately eight times higher dose $(25$ $\mathrm{mg} / \mathrm{kg}$ ) of the zinc compound used in their study.

Diclofenac, zinc-diclofenac or the diclofenac plus zinc acetate combination inhibited the formation of granulomatous tissue in a similar way. Nascimento et al. (19) also reported that complexation of tenoxicam with zinc does not change the antinociceptive and anti-inflammatory activity of this NSAID. These results also agree with those reported by Abou-Mohamed et al. (26) who demonstrated that the simultaneous administration of zinc with diclofenac or indomethacin does not change the activity of these NSAIDs in the carrageenan-induced paw edema model.

We also observed that the diclofenac-

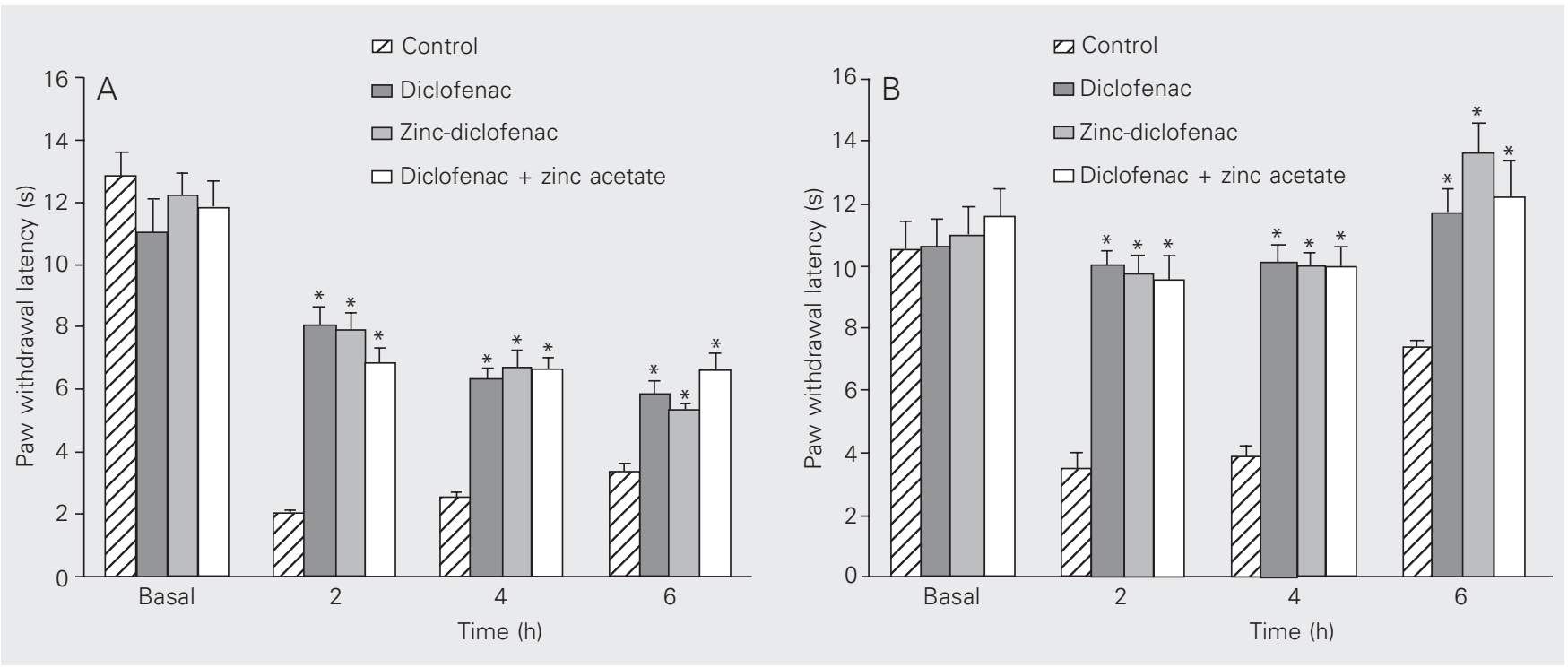

Figure 2. Effect of diclofenac, zinc-diclofenac, and diclofenac plus zinc acetate on the Hargraves model of nociceptive response after per os (A) and intraperitoneal administration (B). Diclofenac $(10 \mathrm{mg} / \mathrm{kg})$, zinc-diclofenac $(11 \mathrm{mg} / \mathrm{kg})$, the association of diclofenac $(10 \mathrm{mg} / \mathrm{kg}) \mathrm{plus}$ zinc acetate $(3.35$ $\mathrm{mg} / \mathrm{kg}$ ) or the corresponding volume of $0.5 \%$ carboxymethylcellulose (control) was administered $2 \mathrm{~h}$ before injection of $1 \%$ carrageenin into the subplantar region of the left hind paw. Data are reported as means \pm SEM for 6 animals. Basal corresponds to the latency for paw withdrawal before the treatments. ${ }^{*} \mathrm{P}<0.05$ compared to control (ANOVA and Duncan test). 
zinc complex does not change the antinociceptive effect of the drug. Nascimento et al. (19) presented similar results for tenoxicam in the model of abdominal writhing induced by acetic acid in mice. However, our results differ from those reported by Jain et al. (25) who demonstrated that zinc-naproxen had a greater antinociceptive effect in the abdominal writhing induced by acetic acid and in the tail-flick test than naproxen alone at the same concentration.

Taken together, the present results indicate that complex formation between an NSAID and zinc does not reduce the antiinflammatory or antinociceptive activity of the drug. When an alteration occurs, it is an increase in the anti-inflammatory activity of the complex, indicating a possible intrinsic anti-inflammatory activity of zinc compounds and providing further support for the use of zinc complexes in the treatment of different inflammatory situations. The relationship of zinc to inflammation is not clear. However, it has been shown that zinc-deficient diets may exacerbate the inflammatory response in experimental animals (27) and treatment with zinc compounds attenuates some signs associated with rheumatoid arthritis in humans (28).

Although the diclofenac plus zinc complex did not change the anti-inflammatory or antinociceptive activity of the NSAID, it reduced its potential to exacerbate cold exposure-induced gastric lesions. The group treated with zinc-diclofenac presented a reduced severity of gastric lesions when compared to the group treated with diclofenac alone. These results are consistent with those reported by Tagliati et al. (18) and Nascimento et al. (19) who observed that the severity of gastric lesions presented by animals treated with piroxicam or tenoxicam complexed with zinc was reduced when compared to that presented by animals treated with the free drugs or with he NSAIDs combined with a zinc compound.

When drugs were administered ip, the difference between the zinc-diclofenac complex and the diclofenac plus zinc acetate combination was observed only for level 1+ lesions. Since $1+$ lesions induce the least discomfort, the use of the complex would not be justified in case of parenteral administration. However, considering oral administration, the presence of zinc, complexed or in combination, is important because it reduces the severity of gastric lesions as a result of both local (13) and systemic (29) effects.

Different models have been used to evaluate the effect of potential antiulcer drugs, raising the question of what model has a greater predictive value. Some studies indicate that the gastric lesions induced by NSAIDs present a higher predictive value than those induced by cold exposure (30). However, others indicate that lesions induced by cold exposure may represent a model with high predictive value since many clinically useful antiulcer drugs, including $\mathrm{H}_{2}$ antagonists and $\mathrm{H}^{+} \mathrm{K}^{+}$ATPase inhibitors, markedly reduce their number and severity (31-33). In the present study, we observed that a diclofenac plus zinc complex resulted in a protective effect in both models, i.e., lesions induced by cold exposure and lesions induced by repeated administration of the NSAID.

In the model of gastric lesions induced by a 7-day treatment, there was no difference among experimental groups when $1+$ and $2+$ lesions were evaluated. However, the severity of $3+$ lesions was markedly reduced in the group treated with zinc-diclofenac. It could be argued that such a reduction resulted from an adaptation of gastric mucosa that may occur after prolonged treatment with the NSAID, as suggested by Skeljo et al. (34). However, this seems to be unlikely since as the reduction of the severity of $3+$ lesions was not observed in the groups treated with diclofenac or with the diclofenac plus zinc combination. The reduction of severity thus observed represents the protective effect of 
zinc when this element is complexed with diclofenac.

Dillon et al. (35), studying zinc and copper complexes with indomethacin, observed distinct situations. Even though both complexes caused less intense intestinal ulceration, copper complex-induced gastric ulceration was less intense than that observed with the zinc complex. According to the authors, the activity of superoxide dismutase may have been partly responsible for the minor ulcerogenicity observed with indomethacin-copper. Concerning the zinc complex, the lack of a technique to measure zinc prevents the evaluation of the relation between this ion and superoxide dismutase.

Different mechanisms have been proposed to explain the gastroprotective effect of zinc compounds. It has been shown that zinc sulfate may stabilize mast cells (36) and lysosome (37) membranes. Regarding zinc acexamate, increased prostaglandin 2 concentrations (12-14) and inhibition of norepinephrine-induced vasoconstriction (38) may explain its gastroprotective effect.

The explanation for the reduced severity of gastric lesion with zinc-diclofenac compared to diclofenac alone is not clear. However, Tagliati et al. (18), in a study of the kinetics of piroxicam and of zinc-piroxicam, observed that the absorption of the complex was slower than absorption of the free drug. A similar situation must occur with zincdiclofenac.

Since the posologic scheme is one of the most important factors in patient compliance with treatment (17), the present results may be of interest by suggesting the use of a single medication with combined anti-inflammatory and gastroprotective effects.

\section{References}

1. Sallmann AR (1986). The history of diclofenac. American Journal of Medicine, 80: 29-33.

2. Arnaldo C (2003). Remédios: cuidado com a overdose. ABCFarma, 139: $26-32$.

3. Todd PA \& Sorkin EM (1988). Diclofenac sodium. A reappraisal of its pharmacodynamic and pharmacokinetic properties, and therapeutic efficacy. Drugs, 35: 244-285.

4. Andrade SE, Martinez C \& Walker AM (1988). Comparative safety evaluation of non-narcotic analgesics. Journal of Clinical Epidemiology, 51: 1357-1365.

5. Ligumsky M, Sestieri M, Karmeli F, Zimmerman J, Okon E \& Rachmilewitz D (1990). Rectal administration of nonsteroidal antiinflammatory drugs. Gastroenterology, 98: 1245-1249.

6. Martin MJ, Marhuenda E \& Alarcon de la Lastra C (1991). Esculine, ranitidine and carbenoxolone: different modes of action on gastric mucosa. General Pharmacology: The Vascular System, 22: 10011004.

7. Wallace JL, Reuter B, Cicala C, McKnight W, Grisham M \& Cirino G (1994). A diclofenac derivative without ulcerogenic properties. European Journal of Pharmacology, 257: 249-255.

8. Bianchi Porro G, Lazzaroni M, Manzionna G \& Pertillo M (1998). Omeprazole and sucralfate in the treatment of NSAID-induced gastric and duodenal ulcer. Alimentary Pharmacology and Therapeutics, 12: 355-360.

9. Giannoukas AD, Baltoyiannis G, Milonakis M, Nastos D, Papagikos L, Kappas AM, Fatouros M, Papadimitriou C \& Cassioumis D (1996). Protection of the gastroduodenal mucosa from the effects of diclofenac sodium: Role of highly selective vagotomy and misoprostol. World Journal of Surgery, 20: 501-506.
10. Matheson AJ \& Figgitt DP (2001). Rofecoxib: a review of its use in the management of osteoarthritis, acute pain and rheumatoid arthritis. Drugs, 61: 833-865.

11. Cho CH, Ogle CW, Wong SH \& Koo MW (1985). Effects of zinc sulphate on ethanol- and indomethacin-induced ulceration and changes in prostaglandin $E_{2}$ and histamine levels in the rat gastric glandular mucosa. Digestion, 32: 288-295.

12. Navarro C, Escolar G, Baños JE, Casanovas LI \& Bulbena O (1988). Effects of zinc acexamate on gastric mucosal production of prostaglandin $\mathrm{E}_{2}$ in normal and stressed rats. Prostaglandins, Leukotrienes and Essential Fatty Acids, 33: 75-80.

13. Bravo L, Escolar G, Navarro C, Fontarnau R \& Bulbena O (1990). Effect of zinc acexamate on gastric lesions induced by aspirin: a morphological study. European Journal of Pharmacology, 190: 5965.

14. Bulbena O, Escolar G, Navarro C, Bravo L \& Pfeiffer CJ (1993). Gastroprotective effects of zinc acexamate against damage induced by nonsteroidal anti-inflammatory drugs: A morphological study. Digestive Diseases and Sciences, 38: 730-739

15. Bandyopadhyay B \& Bandyopadhyay SK (1997). Protective effect of zinc gluconate on chemically induced gastric ulcer. Indian Journal of Medical Research, 106: 27-32.

16. Rodriguez de la Serna A \& Díaz-Rubio M (1994). Multicenter clinica trial of zinc acexamate in the prevention of nonsteroidal antiinflammatory drug induced gastroenteropathy. Journal of Rheumatology, 21: 927-933.

17. Kraag GR, Gordon DG, Menard HA, Russell AS \& Kalish GH (1994). Patient compliance with tenoxicam in family practice. Clinical Therapeutics, 16: 58-93. 
18. Tagliati CA, Kimura E, Nothenberg MS, Santos SRJC \& Oga S (1999). Pharmacokinetic profile and adverse gastric effects of zincpiroxicam in rats. General Pharmacology, 33: 67-71.

19. Nascimento JW, Santos LH, Lima L, Coelho MM, Nothenberg MS, Oga S \& Tagliati CA (1999). Antiinflammatory effect and gastric lesions induced by zinc-tenoxicam in rats. Bollettino Chimico Farmaceutico, 138: 271 (Abstract).

20. Cini R, Giorgi G, Cinquantini A, Rossi C \& Sabat M (1990). Metal complexes of the antiinflammatory drug piroxicam. Inorganic Chemistry, 29: 5197-5200.

21. Niemegeers CJE, Bruggen WV, Awouters F \& Jansen PAJ (1975). The effects of suprofen in rats with implanted cotton pellets. Arzneimittel-Forschung, 25: 1524-1526.

22. Hargraves K, Budner R, Brown F, Flores C \& Joris J (1988). A new and sensitive method for measuring thermal nociception in cutaneous hyperalgesia. Pain, 32: 77-88.

23. Rainsford KD (1975). A synergistic interaction between aspirin, or other non-steroidal anti-inflammatory drugs, and stress which produces severe gastric mucosal damage in rats and pigs. Agents and Actions, 5: 553-558.

24. Szelenyi I \& Thiemer K (1978). Distention ulcer as a model for testing of drugs for ulcerogenic side effects. Archives of Toxicology, 41: 99-105.

25. Jain NK, Amarjit S \& Kulkarni SK (1999). Analgesic, anti-inflammatory and ulcerogenic activity of a zinc-naproxen complex in mice and rats. Pharmacy and Pharmacology Communications, 5: 599-602.

26. Abou-Mohamed G, El-Kashef H, Salem HA \& Elmazar MM (1995). Effect of zinc on the anti-inflammatory and ulcerogenic activities of indomethacin and diclofenac. Pharmacology, 50: 266-272.

27. Milanino R, Marrella U, Morretti E \& Velo GP (1988). Copper and zinc status in rats with acute inflammation: Focus on the inflamed area. Agents and Actions, 24: 356-364.

28. Simkin PA (1976). Oral zinc sulfate in rheumatoid arthritis. Lancet, 11: 539-542.

29. Esplugues JV, Bulbena O, Escolar G, Martin-Bonmati E \& Esplugues $\mathrm{J}$ (1985). Effects of zinc acexamate on gastric mucosal resistance factors. European Journal of Pharmacology, 109: 145-151.

30. Robert A, Leung FW, Kaiser DG \& Guth PH (1989). Potential of aspirin-induced gastric lesions by exposure to cold in rats. Role of acid secretion, mucosal blood flow and gastric mucosal prostanoid content. Gastroenterology, 97: 1147-1158.

31. Muramatsu M, Isobe $Y$, Arai I, Hirose-Kijima $H$, Usuki-Ito $C$, Nagai $H$, Aihara H \& Otomo S (1990). Effects of the new H2-receptor antagonist 3-amino-4-[4-[4-(1-piperidinomethyl)-2-pyridyloxy]-cis-2-butenylamino]-3-cyclobutene-1,2-dione hydrochloride on gastric acid secretion and ulceration. Arzneimittel-Forschung, 40: 49-54.

32. Srivastava SK, Nath C, Gupta MB, Vrat S, Sinha JN, Dhawan KN \& Gupta GP (1991). Protection against gastric ulcer by verapamil. Pharmacology Research, 23: 81-86.

33. Alarcon de la Lastra C, Martin MJ, La Casa M, Lopez A \& Motilva V (1996). Effects of cisapride on ulcer formation and gastric secretion in rats: comparison with ranitidine and omeprazole. General Pharmacology, 27: 1415-1420.

34. Skeljo MV, Cook GA, Elliott SL, Giraud AS \& Yeomans ND (1996). Gastric mucosal adaptation to diclofenac injury. Digestive Diseases and Sciences, 41: 32-39.

35. Dillon CT, Hambley TW, Kennedy BJ, Lay PA, Zhou Q, Davies NM, Biffin JR \& Regtop HL (2003). Gastrointestinal toxicity, antiinflammatory activity and superoxide dismutase activity of copper and zinc complexes of the antiinflammatory drug indomethacin. Chemical Research in Toxicology, 16: 28-37.

36. Cho CH \& Ogle CW (1977). The effect of zinc sulphate on vagalinduced mast cell changes and ulcers in the rat stomach. European Journal of Pharmacology, 43: 315-322.

37. Cho CH, Pfeiffer CJ \& Cheema A (1980). Studies of zinc and lysosomal fragility: possible role in stress ulceration. Pharmacology, Biochemistry, and Behavior, 13: 41-44.

38. Bulbena O, Esplugues JV, Escolar G \& Esplugues J (1989). Effects of zinc acexamate on blood flow and prostanoid levels in the gastric mucosa of the rat. Prostaglandins, Leukotrienes, and Essential Fatty Acids, 36: 119-123. 